\title{
Raphanus sativus ameliorates atherogeneic lipid profiles in hypercholesterolemic rats and hypercholesterolemia-associated peroxidative liver damage
}

\author{
Mozammel Haque, Jahirul Islam, Asiqur Rahaman, Fowzia Akter Selina, Mohammad Azizur \\ Rahman, Mahmudul Hasan, Shahdat Hossain*
}

Laboratory of Alternative Medicine \& Behavioral Neurosciences, Department of Biochemistry and Molecular Biology, Jahangirnagar University, Savar, Dhaka-1342, Bangladesh.

\section{*Correspondence to: shahdat@dhaka.net}

\section{Professor}

Department of Biochemistry and Molecular Biology

Jahangirnagar University

Savar, Dhaka-1342,

Bangladesh.

\begin{abstract}
Objective: Raphanus sativus is a hugely used edible root vegetable. We investigated whether the feeding of the Raphanus sativus hot water extract (RSE) ameliorates atherogenic lipid profile and oxidative stress in hypercholesterolemia. Methods: After feeding of the RSE to hypercholesterolemic rats for 6 weeks, the levels of plasma and hepatic total cholesterol (TC), triglyceride (TG), and plasma high density lipoprotein-cholesterol (HDL-C) and fecal TC levels were studied. The effects of RSE on the hepatic enzymes, namely alanine aminotransferase (ALT), aspartate aminotransferase (AST) and alkaline phosphatase (ALP), the levels of lipid peroxide (LPO) and liver histology were also evaluated. Results: Hypercholesterolemia increased the levels of TC and TG in the plasma and livers. The levels of ALT, AST and ALP in plasma and LPO in the liver also increased. The dietary RSE, however, significantly ameliorated the above atherogenic lipids and liver enzymes. The RSE significantly reduced the levels of LPO in the liver, suggesting an in vivo protection against oxidative stress. The RSE also inhibited the in vitro Fenton's reagent-induced oxidative stress, thus corroborating the in vivo anti-LPO actions of RSE. The levels of hepatic LPO were positively correlated with plasma AST $(r=0.76 ; P<0.05)$ and ALT $(r=0.43 ; P<0.05)$ levels. Histologically, the livers of the RSE-fed hypercholesterolemic rats exhibited lesser fatty droplets and reduced inflammatory cells. Conclusion: Finally, $R$. sativus extract lowers the cardiovascular disease risk factors under hypercholesterolemic situation by increasing the plasma/hepatic clearance of cholesterol and improving the hypercholesterolemia-induced oxidative damage of hepatic tissues.
\end{abstract}

\section{Keywords}

Hypercholesterolemia; Raphanus sativus; Cardiovascular disease; Lipid peroxide

\section{Academic Discipline And Sub-Disciplines}

Food Chemistry, Medicinal Chemistry and Natural Products.

\section{SUBJECT CLASSIFICATION}

Biochemistry

\section{TYPE (METHOD/APPROACH)}

Original Articles

\section{Council for Innovative Research}

Peer Review Research Publishing System

Journal: Journal of Advances in Chemistry

Vol. 7, No. 3

editor@cirworld.com

www.cirjac.com, member.cirworld.com 


\section{INTRODUCTION}

The constitution of plasma membrane of eukaryotic cells is impossible without cholesterol, indicating cholesterol is indispensible for the growth, viability and development of higher organisms. Thus it is obligatory or normal to have cholesterol in our body. However, high level of cholesterol in the blood is a major risk for coronary heart disease, hypertension and stroke [1]. That's why cholesterol is referred to as a double-edged blade. Too much circulatory blood cholesterol slowly builds up in the inner walls of the arteries that feed the heart and brain. Together with other substances, cholesterol then progressively forms plaque and narrows the arteries, leading to atherosclerosis. Therefore, high blood cholesterol has both priming and progressive rule on the atherosclerosis [2]. A plethora of epidemiological, clinical and animal study demonstrates that composition of the diet is a major determinant of high blood cholesterol. A therapeutic dietary modulation can typically reduce $10-15 \%$ of blood cholesterol and is the first choice of hypercholesterolemia treatment [3]. Medications are prescribed when dietary modification is insufficient. Furthermore, the efficacy of the popular pharmacotherapy like statin is in question because of the problems of resistance, side effects and efficiencies. Therefore, evidence-based alternative therapies are still considered as a safe, effective and essential therapeutic intervention toward hypercholesterolemia.

Raphanus sativus, an edible root vegetable, belongs to the Brassicaceae family. It is commonly known as radish (English), Daikon (Japanese), locally as Mula (Bengali) and consumed throughout the world. It was domesticated in Europe in preRoman times [4]. Raphanus means 'quickly appearing' and refers to the rapid germination of these plants. The common name 'radish' is derived from Latin radix (root). Radishes are rich in ascorbic acid, folic acid, vitamin B6, riboflavin, potassium, magnesium, copper, and calcium [5]. White radish (Raphanus sativus) has medicinal implication from a long time in traditional Indian and Japanese medicine beside the food value. It has anti-tumorigenic (Kim et al., 2011) [6], antimutagenic (Nakamura et al., 2008) [7], anti-diabetic (Shukla et al., 2010) [8] property. Raphanus sativus increases the serum HDL in normal rats [9]. In rats with a high-fat diet, the extract of the Raphanus sativus repairs epithelium and increases enterocytes [10]. Raphanus sativus is produced in huge amounts (200840 tons) in Bangladesh [11]; however, the medicinal values of this root vegetable are largely unknown in Bangladesh. We consider that the hot water extract rather than the ethanol/methanol- and/or nonpolar extract would pertinently reflect the real effects of the consumption of Raphanus sativus as well as confirm the true medicinal values of this root. Therefore, the aim of the present study was to evaluate the effect of $R$. sativus hot water extract on atherogenic lipid profile and also to study the possible changes in the microscopic structure of the liver in normocholesterolemic and experimentally-induced hypercholesterolemic rats.

\section{METHODS AND MATERIALS}

\section{Collection of plant materials and extraction}

Fresh $R$. sativus root vegetables were purchased from local market. The plant materials were identified and authenticated by the Department of Botany, Jahangirnagar University, Savar, Dhaka. The roots were washed and blended by a blender. Blended radish was subjected to the exhausted extraction using de-ionized water as the extraction solvent. The solvent was evaporated under reduced pressure using rotary evaporator at $100 \stackrel{\circ}{ } \mathrm{C}$. The thick residue of extracts were then stored at $4^{\circ} \mathrm{C}$ until further study.

\section{Total polyphenol, flavonoid and vitamin C contents of Raphanus Sativus hot water extract}

Total polyphenols and flavonoids content of the extracts were determined following the methods of Hossain et al. (2013) [12]. The concentration of total phenols was determined as gallic acid equivalents ( $\mu \mathrm{g}$ of GAE/mg of extract). Quercetin was used as standard for the determination of flavonoids and the concentration of total flavonoid in the extract was determined as quercetin equivalents ( $\mu \mathrm{g}$ of $\mathrm{QE} / \mathrm{mg}$ of extract). Vitamin C content of the extract was estimated by the method of Omaye et al. (1994) [13]. Ascorbic acid was used as standard. The vitamin C content of extract was calculated as ascorbate equivalents ( $\mu \mathrm{g}$ of $\mathrm{AE} / \mathrm{mg}$ of extract).

\section{In vitro antioxidant activity of Raphanus Sativus hot water extract}

Evaluation of in vitro antioxidant activity of Raphanus Sativus hot water extract was conducted by the following assays: $\mathrm{i}$. DPPH-free radical scavenging activity, ii. Hydroxyl radical scavenging activity, iii Total reducing power ability, and iv. The ability of inhibiting Fenton's reagent-induced in vitro oxidative stress.

\section{i. DPPH-free radical scavenging activity}

Antioxidative power of the Raphanus sativus hot water was analyzed by its DPPH radical scavenging activity, as described previously [14]. The free radical scavenging effect of radish was compared with that of the quercetin and BHT using equimolar concentrations with equal reaction volumes. Antioxidant activity was expressed as the concentration of the extract $\left(\mathrm{IC}_{50}\right)$ required to decrease the absorbance of the DPPH by $50 \%$. Percentage (\%) of radical inhibition was calculated from the following equation:

$$
\% \text { Radical Inhibition }=\{(\text { Absorbance of Control }- \text { Absorbance of Sample }) / \text { Absorbance of Control })\} \times 100
$$

\section{ii. Hydroxyl Radical scavenging activity}

The hydroxyl radical scavenging assay was determined according to the method of Smirnoff (1989) [15]. The reaction mixture contained $1.0 \mathrm{ml}$ of $1.5 \mathrm{mM} \mathrm{FeSO}_{4}, 0.7 \mathrm{ml}$ of $6 \mathrm{mM}$ hydrogen peroxide, $0.3 \mathrm{ml}$ of $20 \mathrm{mM}$ sodium salicylate and 
varying concentrations of the extract. After incubation of 1 hour at $37^{\circ} \mathrm{C}$, the absorbance of the hydroxylated salicylate complex was measured at $562 \mathrm{~nm}$. The percentage of scavenging effect was calculated as,

$$
\text { Scavenging activity }=\left[1-\left(A_{1}-A_{2}\right) / A_{0}\right] \times 100 .
$$

Where, $A_{0}$ was the absorbance of the control (without extract), $A_{1}$ was the absorbance in the presence of the extract and $\mathrm{A}_{2}$ was the absorbance without sodium salicylate. Hydroxyl radical scavenging activity was expressed as the concentration of the extracts $\left(\mathrm{IC}_{50}\right)$ required to decrease the absorbance by $50 \%$. The value was determined graphically by plotting the absorbance data (\% of inhibition of hydroxyl radical) against the concentration using the slope of the nonlinear regression.

\section{iii. Reducing power ability}

The reducing power of the extracts was estimated following the methods of Hossain et al. (2013) [12], as described previously [16], using quercetin as standard. The reducing power of the extract was calculated as quercetin equivalents ( $\mu \mathrm{g}$ of $\mathrm{QE} / \mathrm{mg}$ of extract).

\section{iv. In vitro Anti-lipid peroxidation (anti-LPO) potential}

For the determination of in vitro anti-lipid peroxidation ability, six rats were sacrificed and whole livers were surgically removed and perfused with ice-cold saline. The liver tissues were then homogenized (100 mg of tissue/ml of buffer) in phosphate buffer $(50 \mathrm{mM}, \mathrm{pH} 7.4)$ using Polytron tissue homogenizer (Kinematica, USA). In vitro anti-lipid peroxidation study was performed by exposing the liver tissue homogenate to Fenton's reagent $\left[\mathrm{H}_{2} \mathrm{O}_{2}(45 \mathrm{mM})+\mathrm{FeSO}\right.$ (2mM)] without (control) or with $R$. sativus hot water extract. The reaction mixtures were then incubated at room temperature for 4 hours. Afterwards, the amount of malondialdehyde was determined as indicator of lipid peroxidation following the methods of Hossain et al., 2004, 2011 [17, 18], as described previously. Level of lipid peroxidation of hepatic tissue was calculated as $\mathrm{nmol} / \mathrm{mg}$ of protein.

\section{Spectrophotometric determination of saponin content in the R. sativus extract}

Total saponin content of the $R$. sativus was determined following anisaldehyde colorimetric assay as previously described $[19,20]$. The thick residue of the hot water extract was used for the assay. The following color developing reagent solutions were prepared: (A) $0.5 \mathrm{ml} \mathrm{p}$-anisaldehyde and $99.5 \mathrm{ml}$ ethyl acetate, and (B) $50 \mathrm{ml}$ concentrated sulfuric acid and $50 \mathrm{ml}$ ethyl acetate. $2.0 \mathrm{ml}$ of radish extract of different concentrations were incubated with $1.0 \mathrm{ml}$ of each of the solution $A$ and $B$ for 10 minutes at $60^{\circ} \mathrm{C}$. After the incubation period, the reaction mixture was cooled for another 10 minutes and the amount of color complex was determined at $430 \mathrm{~nm}$, which is directly proportional to the concentration of saponin in the extract. The saponin content was calculated against the glycyrrhizic acid (a triterpenoid saponin glycoside) standard and expressed as equivalents/mg of extract.

\section{Animals}

Thirty two male Wistar rats ( 9 weeks of age) of weight $110 \mathrm{~g}-120 \mathrm{~g}$ were used in the present study. All the rats were housed at $25^{\circ} \mathrm{C} \pm 2^{\circ} \mathrm{C}$ under $12 \mathrm{~h}$ dark-light cycles in standard plastic cages (bedding was wood chips) and acclimatized to the laboratory conditions for one week prior to the commencement of the treatment. All the rats were allowed free access to basal diet and tap water. The rats in this study were cared for and sacrificed in accordance with the ethical norms approved by Bangladesh Association for Laboratory Animal Science.

\section{In vivo experimental design}

Experimental hypercholesterolemia was induced by feeding rats a cholesterol enriched diet prepared by supplementing standard diet with $1 \%$ cholesterol and $1 \%$ cholic acid. Thirty two rats were randomly divided into four groups each consisting of eight rats: Control rats (Con), maintained with standard diet and orally administered with normal saline; Raphanus sativus hot water extract-fed rats (RSE), maintained with standard diet and orally administered with $R$. sativus hot water extract rats at a dose of $300 \mathrm{mg} / \mathrm{kg}$ body weight daily; Hypercholesterolemic rats (HC), maintained with $1 \%$ cholesterol-enriched diet and orally administered normal saline; RSE-fed hypercholesterolemic rats (HC+RSE), maintained with $1 \%$ cholesterol and orally administered with RSE at a dose of $300 \mathrm{mg} / \mathrm{kg}$ body weight daily. All rats had a free access to respective diet. The intragastric administration of the extract was continued for six weeks. Food and fluid intake of all group rats were measured at regular intervals while the body weight was monitored regularly.

\section{Separation of plasma and hepatic tissue preparation}

After 24 hours of last treatment, overnight fasted rats were sacrificed under light anesthesia (100 mg ketamine $/ \mathrm{kg}$ body weight) and blood was collected into heparinized tubes. Blood was then centrifuged at $2500 \mathrm{rpm}$ for 10 minutes at $25^{\circ} \mathrm{C}$ to separate the plasma and erythrocytes. The plasma and erythrocytes samples were stored at $-20^{\circ} \mathrm{C}$ up to further analyses. The liver excised immediately and washed by physiological saline perfusion. The washed tissues were minced and homogenized with ice cold phosphate buffer $(50 \mathrm{mM}, \mathrm{pH} 7.4)$ and stored at $-20{ }^{\circ} \mathrm{C}$ until further use. Two rats from each group were used for liver histological studies.

\section{Analyses of the plasma biochemical indices}

The plasma concentration of triglycerides (TG), total cholesterol (TC) and high density lipoprotein-cholesterol (HDL-C) were analyzed colorimetrically using commercial kit (Randox Laboratories Ltd, UK), whereas low density lipoproteincholesterol (LDL-C) was calculated from Friedewald formula (1992) [21]. Atherogenic index was also calculated by the 
equation reported by Ikewuchi \& Ikewuchi (2009) [22]. The plasma levels of aspartate transaminase (AST), alanine transaminase (ALT) and alkaline phosphatase (ALP) were analyzed colorimetrically using commercial diagnostic kit (Randox Laboratories Ltd, UK) to estimate hepatic functional status.

\section{Analysis of hepatic lipid peroxide (LPO)}

The level of hepatic lipid peroxide was analyzed by the estimation of the thiobarbituric acid reactive substances (TBARs) of liver tissue as described by Hossain et al., $(2004,2011)[17,18]$. Briefly, tissue homogenates $(0.1 \mathrm{ml})$ from each liver were added to $0.1 \mathrm{ml}$ of $8.1 \%(\mathrm{w} / \mathrm{v})$ sodium dodecylsulphate, $2 \mathrm{ml}$ of $0.4 \%$ thiobarbituric acid in $20 \%$ acetic acid $(\mathrm{pH} 3.5)$ and $0.1 \mathrm{ml}$ distilled water. Each tube was tightly capped and heated at $95^{\circ} \mathrm{C}$ for one hour. After cooling the tubes with tape water, $2 \mathrm{ml}$ of $\mathrm{n}$-butanol-pyridine $(15: 1, \mathrm{v} / \mathrm{v})$ was added and shaken vigorously for about 10 minutes. The tubes were then centrifuged at $1000 \times \mathrm{g}$ for 10 minutes at room temperature (Digital centrifuge; DSC-1512SD). The absorbance of the supernatant fraction was measured at $532 \mathrm{~nm}$. TEP (1,1,3,3-tetraethoxypropane) was utilized as standard. The levels of LPO were expressed as $\mathrm{nmol} / \mathrm{mg}$ of protein of the tissue homogenate.

Total protein was estimated by the method of Lowry et al. (1951) [23].

\section{Analyses of hepatic triglyceride and total cholesterol}

The content of hepatic triglyceride and total cholesterol were analyzed as described previously Hossain et al., (2011) [17, 18]. Hepatic triglyceride and total cholesterol content were expressed as $\mathrm{mg} / \mathrm{g}$ of protein.

\section{Analysis of fecal cholesterol level}

Dried rat feces were powdered and then subjected to fecal cholesterol analysis following Hossain et al., (2011) [17] and expressed as $\mathrm{mg} / 100 \mathrm{mg}$ of dry stool.

\section{Histopathological examination}

Livers of the sacrificed rats were fixed in $10 \%$ formalin solution. The fixed specimens were then trimmed, washed, and dehydrated in ascending grades of alcohol. These specimens were cleared in xylene, embedded in paraffin, sectioned at 4-6 $\mu \mathrm{m}$ of thickness using a microtome (Leica CM 1850, Leica Microsystems GmbH, Wetzlar, Germany). Sections were mounted (egg albumin and glycerol smearing) and stained with Hematoxylin and Eosin. The microscopic observation was done by fluorescent microscope normal spectra (Nikon eclipse E200) in 40X and 100X. The picture was taken by digital camera attached to it.

\section{Statistical analysis}

The results are expressed as mean \pm SEM (standard error of mean). All parameters for inter-group differences were analyzed by one-way ANOVA, followed by Fisher's protected least square differences (PLSD) for post hoc comparisons. Correlation was evaluated by simple linear regression analysis. The statistical programs used were StatView ${ }^{\circledR} 4.01$ (MindVision Software, Abacus Concepts, Inc., Berkeley, CA, USA) and GRAPHPAD PRISM®) (version 5.00; GraphPad Software Inc., San Diego, CA, USA). A level of $P<0.05$ was considered as statistically significant.

\section{RESULTS}

\section{Antioxidant status and saponin content of the R. sativus hot water extract}

The hot water extract of the $R$. sativus had considerable amounts of antioxidant phytochemicals, such as total polyphenols, flavonoids, and vitamin C (Table 1). The extract also displayed DPPH- and hydroxyl-radical scavenging activity, concurrently with reducing power ability (Table 1).

The saponin content of the extract was $54.32 \pm 2.6 \mu \mathrm{g}$ of glycyrrhizic acid equivalents $/ \mathrm{mg}$ of extract

\section{Effect of $R$. sativus extract on in vitro anti-LPO formation ability}

Incubation of liver homogenate with Fenton's reagent significantly induced the oxidative stress in the hepatic tissues, as indicated by the increased levels of lipid peroxide (LPO). Fenton's reagent-instigated oxidative stress, however, was inhibited in the presence of $R$. sativus extract. $R$. sativus extract alone did not induce any oxidative stress (Fig 1A).

\section{Effect of $R$. sativus extract on food intake and body weight}

The administration of $R$. sativus extract had no significant effect on the food intake in either of the rat groups. The feeding of cholesterol-enriched diet significantly $(\mathrm{P}<0.05)$ increased the body weight of the hypercholesterolemic $(\mathrm{HC})$ rats, when compared with that of the control rats. $R$. sativus extract significantly $(\mathrm{p}<0.05)$ decreased the body weight of the $\mathrm{HC}+\mathrm{RSE}$ rats.

\section{Effect of $\boldsymbol{R}$. sativus extract on plasma lipid profile}

The levels of plasma TC, TG, and LDL-C were significantly increased $(\mathrm{P}<0.05)$ in the hypercholesterolemic $(\mathrm{HC})$ rats, as compared to those of the control rats (Con). The feeding of the $R$. sativus extract, however, significantly $(p<0.05)$ decreased the levels of these atherogenic lipids in the HC+RSE rats. The levels of HDL-C increased both in the HC and $\mathrm{HC}+\mathrm{RSE}$ rats, as compared to that of the control (Con) rats. Feeding of the $R$. sativus extract alone significantly reduced the plasma TG levels of the RSE rats. Finally, the atherogenic index (log[TG/ HDL-C]) reduced by $24 \%$ in the $\mathrm{HC}+\mathrm{RSE}$ 
rats, when compared with those of the $\mathrm{HC}$ rats and by $21 \%$ in RSE rats with respect to those of the control (Con) rats (Table 2).

\section{Effect of $R$. sativus extract on hepatic TG and TC}

The hepatic TG and TC contents were increased by $225 \%$ and $335 \%$, respectively, in the hypercholesterolemic (HC) rats, when compared with those of the control rats. Feeding of $R$. sativus extract, however, significantly $(P<0.05)$ reduced the hepatic TC and TG contents of the HC+RSE rats. $R$. sativus extract feeding alone reduced the hepatic contents of TC and TG in the RSE, however, the effects were not significant, when compared to those of the control (Con) rats.

\section{Effect of $\boldsymbol{R}$. sativus extract on fecal cholesterol level}

The feeding of $R$. sativus extract significantly $(\mathrm{P}<0.05)$ increased the levels of fecal TC both in the RSE-alone and the $\mathrm{HC}+\mathrm{RSE}$ rats, when compared with those of the control and $\mathrm{HC}$ rats, respectively.

\section{Effect of $\boldsymbol{R}$. sativus extract on plasma hepatic function-related enzymes}

The plasma levels of alanine aminotransferase (ALT), aspartate aminotransferase (AST) and alkaline phosphatase (ALP) were significantly $(\mathrm{P}<0.05)$ increased in the hypercholesterolemic $(\mathrm{HC})$ rats than those of the control (Con) rats. $A$ significant $(p<0.05)$ reduction in the levels of these enzymes were observed in the HC+RSE rats due to oral administration of $R$. sativus extract. The feeding of the RSE-alone also decreased (numerically) the levels of ALT, AST and ALP in the RSE rats, when compared to those of the control (Con) rats, however, the effect on the ALP only was significant (Table 2).

\section{Effect of $\boldsymbol{R}$. sativus extract on in vivo levels of hepatic LPO}

The levels of lipid peroxide (LPO) in hepatic tissues significantly increased in the hypercholesterolemic (HCG) rats. Oral administration of $R$. sativus extract caused a significant $(\mathrm{p}<0.05)$ inhibition of high cholesterol-induced rise of hepatic LPO levels in the $\mathrm{HC}+\mathrm{RSE}$ rats than those of the $\mathrm{HC}$ rats. The LPO level in rats treated with $R$. sativus extract (RSE)-alone was also lower though insignificantly ( $p>0.05)$, than that of the control (Con) rats (Fig 1B).

\section{Correlation study}

The simple regression analysis revealed a strong significant $(r=0.84 ; P<0.05)$ positive correlation between the plasma total cholesterol (TC) and fecal cholesterol levels. The hepatic LPO levels also exhibited a strong significant $(r=0.76$; $P$ $<0.05)$ positive correlation with the plasma levels of AST and a moderate significant $(r=0.43 ; P<0.05)$ positive correlation with the plasma levels of ALT.

\section{Histological analysis}

A normal radiating hepatocyte pattern with central vein was found in histological analysis of the liver of the control rats (Con) and extract-fed (RSE) rats. At the cellular level, the livers of control and RSE rats (RSE) exhibited the normal histological features like polyhedral hepatocytes, normal vacuolation and intact parenchyma with local tissue macrophages (kupffer cell) only. In the hypercholesterolemic rats $(\mathrm{HC})$, the characteristic radiating hepatocyte pattern was lost with the presence of circulatory inflammatory cells in the central vein. There were severe fatty degeneration with pyknotic nuclei and loss of polyhedral shapes of hepatocytes with massive infiltration of the inflammatory cells. But the RSE extract-fed hypercholesterolemic (HC+RSE) rats exhibited a moderately radiating hepatocyte pattern with a few circulatory inflammatory cells in the central vein. The polyhedral shapes of the hepatocytes were restored with lesser fatty droplets and reduced inflammatory cells.

\section{DISCUSSION}

The results of the present investigation clearly demonstrate that $R$. sativus hot water extract decreases plasma and hepatic atherogenic lipids, such as total cholesterol (TC) and triacylglycerol (TG), concurrently with increases in the excretion of fecal cholesterol both in the normocholesterolemic and experimentally-induced hypercholesterolemic rats. The status of hepatic enzyme parameters and histological features were also improved by the treatment of the extract.

The supplementation of basal diet with $1 \%$ cholesterol successfully induced hypercholesterolemia, as indicated by the significant increases (by $>150 \%$ ) of plasma total cholesterol with respect to that of the control rats. The results of the increased levels of plasma TC in the hypercholesterolemic $(\mathrm{HC})$ rats were consistent with their elevated hepatic TC and TG contents. Furthermore, a substantial lipid deposition was observed by histology in the hepatic tissues.

Feeding of the hot water radish extract to the $\mathrm{HC}+\mathrm{RSE}$ rats significantly reduced the level of plasma TC and LDL-C as well as hepatic TC and TG content with respect to those of the hypercholesterolemic $(\mathrm{HC})$ rats. The reductions of circulatory TC and hepatic lipid content were consistent with the extract-induced rise of the fecal excretion of cholesterol in the $\mathrm{HC}+\mathrm{RSE}$ rats. Thus, we speculate that the hypocholesterolemia effect of the extract is accomplished by the increased fecal excretion of the cholesterol, at least, to some extent. A significant $(r=0.84 ; P<0.05)$ positive correlation between the plasma TC and fecal cholesterol level further strengthen our proposition. Reductions of plasma TC and LDL-C indicate increased clearance of cholesterol from circulation by either the increased excretion of dietary cholesterol or decreased hepatic cholesterol synthesis [17]. But within our experimental limit, increased excretion of dietary cholesterol seems to be the possible of mode of plasma clearance of TC. Saponins are a structural analog of cholesterol and could be one of responsible phytochemicals for hypocholesterolemic effect of the radish extract $[24,25]$. Saponins form strong insoluble complexes with cholesterol [26]. Dietary saponins also reduce blood cholesterol levels in mammals [27]. Malinow et al. 
(1977) [28] reported that saponin has hypocholesterolemic activity in non-human primates. Chapman et al. (1997) [29] reported that the basal serum cholesterol level of Masai people of East Africa is low in spite of a diet rich in animal fats, and the low cholesterol levels were attributed to the saponin-rich herbs of the Masai diet. Kim et al. (2003) [30] also reported that saponin decreases the TC and LDL-C levels in the blood plasma of hypercholesterolemic patients. These effects are achieved by the binding of bile acids and cholesterol by saponins. Saponins cause a depletion of body cholesterol by preventing its reabsorption, thus increasing its excretion, in much the same way as other cholesterollowering drugs, such as cholestyramine. The radish extract used in our experiment had substantial amount of saponin. From these reports (24-30) and our results, it is thus speculated that the ingestion of saponin-rich foods such as $R$. sativus might had increased fecal excretion of cholesterol, and so doing, it decreased plasma/hepatic cholesterol in the present investigation. The atherogenic indices were reduced significantly both in the normocholesterolemic and hypercholesterolemic rats as a result of oral administration of $R$. sativus extract (Table 2). Atherogenic indices are powerful indicators of the risk of cardiovascular diseases. The higher the atherogenic indices value, the higher the risk for developing cardiovascular diseases and vice versa. Low atherogenic indices are protective against coronary heart disease [31]. Thus, the $R$. sativus extract possess significant protective effects against cardiovascular complications.

The impact of oral administration of $R$. sativus extract on the hepatic status was studied by estimating liver-function specific enzyme markers like ALT, AST, ALP and the hepatic tissue levels of lipid peroxide (LPO). Diet-induced hypercholesterolemia caused a significant rise of the plasma levels of ALT, AST and ALP with respect to those of the control rats. Feeding of the $R$. sativus extract to the HC+RSE rats, however, restored the levels of these liver enzymes to those of the control rats. Qualitatively consistent with our studies, the water extract of the Raphanus sativus leaf significantly reduced the SGOT, SGPT and SALP activities in paracetamol-induced hepatotoxicity [32], which is frequently seen accompanied with increased oxidative stress. High cholesterol diet significantly increased the levels of LPO in the livers tissues of hypercholesterolemic $(\mathrm{HC})$ rats than that of the control rats. However, the feeding of the radish extract significantly decreased the hepatic levels of LPO, thus demonstrating an active antioxidative effect of the extract against hypercholesterolemia-instigated in vivo oxidative stress. The in vivo antioxidative effect was further reproduced in in vitro experiments. Fenton's reagent-induced oxidative stress in the liver homogenates was significantly inhibited in the presence of the $R$. sativus extract. Therefore, the hypercholesterolemic effect of the $R$. sativus extract forgoes any harmful effect rather improved hypercholesterolemia-induced peroxidative damage of hepatic tissues. The significant positive correlations between the hepatic LPO and plasma ALT and/or AST also supported the antioxidative effects. Histological data also provided strong evidence of the positive effects of the radish extract on the cellular morphology. The livers of the HC+RSE exhibited less fatty degeneration/droplets, less loss of polyhedral shape of hepatocytes, decreased inflammatory cells and peroxidative damage, as compared to those of the livers of the hypercholesterolemic (HC) rats. Lipid peroxidation, accompanied with hypercholesterolemia in the present study, might be ascribed to the oxidative stress and elevated levels of ALT, AST and ALP in the plasma. Alanine aminotransferase (ALT) and aspartate aminotransferase (AST) are the most specific indicators of hepatic injury and representative markers of hepatocellular necrosis [33]. Rises in the levels of these enzymes might correspond to hepatocyte necrosis or abnormal membrane permeability, while reduction indicates healing of hepatic parenchyma [33]. Hypercholesterolemia and associated lipid deposition are associated with the aberration of the hepatic antioxidative defense system and consequent oxidative stress [34]. Fenton's reagent generates highly reactive hydroxyl radicals $(\bullet \mathrm{OH})$ by utilizing hydrogen peroxide $\left(\mathrm{H}_{2} \mathrm{O}_{2}\right)$. These radicals get into cellular system and initiate a chain of oxidation reactions that ultimately lead to lipid peroxidation and cause membrane damage [35]. The exact mechanism(s) through which RSE inhibited the oxidative stress in the hepatic tissues both in the in vivo and in vitro conditions remains to be determined. Antioxidant and radical scavenging activity of $R$. sativus root water extract was attributed to its catechin content, the most abundant phenolic compound in radish water extract [36]. Antioxidants protect cells against the damaging effects of reactive oxygen species which results in oxidative stress leading to cellular damage [37]. Free radicals generated in the body can be removed by the body's own natural antioxidant defenses such as glutathione or catalases [38]. Therefore this deficiency had to be compensated by making use of natural exogenous antioxidants, such as vitamin C, vitamin E, flavones, beta-carotene and natural products in plants [39-41]. The presence of polyphenols/flavonoids in the extract and/or the DPPH-free radical scavenging ability of the RSE might contribute to the decreased levels of LPO in the livers of the HC+RSE rats. Finally, our present study clearly demonstrates that the saponin-containing extract of $R$. sativus lowers the cardiovascular disease risk in hypercholesterolemia by increasing the plasma and hepatic clearance of cholesterol, and inhibiting the aberration of hepatic function, if any, and finally, improves the hypercholesterolemia-induced peroxidative damage of hepatic tissues.

\section{CONCLUSION}

It is vitally important to manage hypercholesterolemia effectively because it is a modifiable risk factor. In the search for curative and preventive treatments for hypercholesterolemia, the essential thing is to reduce the concentration of intestinal, hepatic, biliary and plasma cholesterol. The feeding of the radish hot water extract was capable of increasing the fecal excretion of cholesterol, which is a reflection of reduction of cholesterol from the plasma, intestine and liver. The results of the present investigation thus could be considered to have significant interest for the hypercholesterolemic patients suffering from cardiovascular dysfunctions in the developing countries like Bangladesh. The study might also have an important impact on the normocholesterolemic individuals who intend to protect against cardiovascular dysfunctions. $R$. sativus extract could, therefore, be used as an alternative to hypocholesterolemic drug. 


\section{Acknowledgements}

This work was supported, in part, by a Grant-in-Aid from the University Grant Commission (UGC) and Higher Education Quality Enhancement Program Projects at the Dept. of Biochemistry and Molecular Biology, Jahangirnagar University, Savar, Dhaka, Bangladesh. No conflict of interest exists in this work.

\section{References}

1. Mannu GS, Zaman MJ, Gupta A, Rehman HU, Myint PK. Update on guidelines for management of hypercholesterolemia. Expert Rev Cardiovasc Ther. 2012; 10:1239-49.

2. Ravnskov U. Is atherosclerosis caused by high cholesterol? QJM. 2002; 95: 397-403.

3. Fiorenza AM, Branchi A, Cardenà A, Molgora M, Rovellini A, Sommariva D. Serum cholesterol levels in patients with cancer. Intl J Clin Lab Res. 1996; 26: 37-42.

4. Lewis-Jones LJ, Thorpe JP, Wallis GP. Genetic divergence in four species of the genus Raphanus: Implications for the ancestry of the domestic radish R. sativus. Biolog J Linnean Soc. 1982; 18:35-48.

5. Jan M, Badar A. Effect of crude extract of Raphanus sativus roots on isolated trachea of albino rat. Pak. J. Physiol. 2012; 8: 23-26.

6. Kim WK, Kim JI, Jeong DH, Chun YH, Kim SH, Cho KJ, Chang MJ, Radish (Raphanus sativus L. leaf) ethanol extract inhibits protein and mRNA expression of ErbB2 and ErbB3 in MDA-MB-231 human breast cancer cells. Nutr Res Pract. 2011; 5: 288-293

7. Nakamura Y, Nakamura K, Asai Y, Wada T, Tanaka K, Matsuo T, et al. Comparison of the glucosinolatemyrosinase systems among Daikon (Raphanus sativus, Japanese white radish) varieties. J Agr Food Chem. 2008; 56: 2702-2707.

8. Shukla S, Chatterji S, Mehta S, Rai PK, Singh RK, Yadav DK, et al. Antidiabetic effect of Raphanus sativus root juice. Pharm Biol. 2010; 49: 32-37.

9. Taniguchi H, Muroi R, Kobayashi-Hattori K, Uda Y, Oishi Y, Takita T. Differing effects of water-soluble and fatsoluble extracts from Japanese radish (Raphanus sativus) sprouts on carbohydrate and lipid metabolism in normal and streptozotocin-induced diabetic rats. J Nutr Sci Vitaminol. 2007; 53: 261-6.

10. Sipos $P$, Hagymási K, Lugasi A, Fehér E, Blázovics A. Effects of black radish root (Raphanus sativus $L$. var niger) on the colon mucosa in rats fed a fat rich diet. Phytother Res. 2002; 16:677-9.

11. Year book of Agricultural statistics of Bangladesh Bureau of statistics (BBS), Ministry of Planning Dhaka, 2000, 94-102

12. Hossain S, Rahman M, Fatima N, Haque M, Islam J. Leucas zeylanica (L.) R. Br. protects ethanol and hydrogen peroxide-induced oxidative stress on hepatic tissue of rats. Intl Curr Pharmaceut J. 2013; 2: 148-151.

13. Omaye ST, Turnbull JD Sauberlich HE. Selected methods for the determination of ascorbicacid in animal cells, tissues and fluids. Methods in Enzymology. 1979; 62, 3-11.

14. Hossain S, Rahaman A, Taslima Nahar, Basunia MA, Mowsumi FR, Uddin B, et al. Syzygium cumini (L.) skeels seed extract ameliorates in vitro and in vivo oxidative potentials of the brain cerebral cortex of alcohol-treated rats. Orient Pharm Exp Med. 2012; 12:59-66.

15. Smirnoff N, Cumbes QJ. Hydroxyl radical scavenging activity of compatible solutes. Phytochemistry. 1989; 28: 1057-60.

16. Oyaizu M. Studies on products of browning reactions: antioxidative activities of products of browning reaction prepared from glucosamine. Japanese J Nutr 1986; 44: 307-15

17. Hossain S, Chowdhury IH, Basunia MA, Nahar T, Rahaman A, Choudhury BK, et al. Syzygium cumini Seed Extract Protects the Liver Against Lipid Peroxidation with Concurrent Amelioration of Hepatic Enzymes and Lipid Profile of Alcoholic Rats. J Compl Integr Med. 2011; 8: 1-17.

18. Shahdat $H$, Hashimoto $M$, Shimada $T$, Shido O. Synaptic plasma membrane-bound acetylcholinesterase activity is not affected by docosahexaenoic acid-induced decrease in membrane order. Life sci. 2004; 74: 3009-24.

19. Uematsu Y, Hirata K, Saito K, Kudo I. Spectrophotometric determination of saponin in Yucca extract used as food additive. J AOAC Intl. 2000; 83(6):1451-4.

20. Hostettmann K, Marston A. Saponins. Chemistry and Pharmacology of Natural Products. $1^{\text {st }}$ edition: Cambridge University Press; 1995.

21. Cohn JS, McNamara JR, Schaefer EJ. Lipoprotein Cholesterol Concentrations in the plasma of Human Subjects as Measured in the fed and Fasted States. Clin Chem. 1988; 34: 2456-59. 
22. Ikewuchi JC, Ikewuchi CC. Alteration of plasma lipid profiles and atherogenic indices by Stachytarpheta jamaicensis L. (Vahl). Biokemistri 2009; 21: 71-77.

23. Lowry OH, Rosebrough NJ, Farr AL, Randall RJ. Protein measurement with the Folin reagent. J Biol Chem 1951; 193: 265-75.

24. Amarowicz R, Shimoyamada M, Okubo K. Hypocholesterolemic effects of saponins. Rocz Panstw Zakl Hig. 1994; 45:125-30.

25. Zhao HL, Harding SV, Marinangeli CP, Kim YS, Jones PJ. Hypocholesterolemic and anti-obesity effects of saponins from Platycodon grandiflorum in hamsters fed atherogenic diets. J Food Sci. 2008 73:H195-200.

26. Lindahl IL, Shalkop WT, Dougherty RW, Thompson CR, Van Atta GR, Bickoff EM, et al. Alfalfa saponin. Studies on their chemical, pharmacological, and physical properties in relation to ruminant bloat. USDA Technical Bulletin No. 1161, 1957.

27. Oakenfull, D. and Sidhu, G. S., Saponins, In Cheeke, P. R. (ed.). Toxicants of plant origin. vol. 2. CRC Press, Boca Raton, pp. 97-141, 1989.

28. Chapman L, Johns T, Mahunnah RL A, Saponin-like in vitro characteristics of extracts from selected non-nutrient wild plant food additives used by Masai in meat and milk based soups. Ecol. Food Nutr 1997:36; 1-22.

29. Malinow MR, McLaughlin P, Kohler GO, Livingston AL, Prevention of elevated cholesterolemia in monkeys. Steroids 1977; 29: 105-110.

30. Kim SW, Park SK, Kang SI, Kang HC, Oh HJ, Bae CY, et al. Hypocholesterolemic Property of Yucca schidigera and Quillaja saponaria Extracts in Human Body. Arch Pharm Res. 2003; 26:1042-1046.

31. Chigozie IJ, Chidinma IC. Positive moderation of the hematology, plasma biochemistry and ocular indices of oxidative stress in alloxan-induced diabetic rats, by an aqueous extract of the leaves of Sansevieria liberica Gerome and Labroy. Asian Pac J Trop Med. 2013; 6: 27-36.

32. Anwar R, Ahmad M., Studies of Raphanus sativus as hepato protective agent. J Med Sci. 2006; 6: 662-665.

33. Mowsumi FR, Rahman MM, Rahaman A, Hossain S. Preventive Effect of Ganoderma lucidum on Paracetamolinduced Acute Hepatotoxicity in Rats. J Sci Res. 2013; 5: 573-578.

34. Hossain H, Hashimoto $\mathrm{H}$, Choudhury EK, Alam N, Hossain S, Hasan $\mathrm{H}$ et al. Dietary mushroom (Pleurotus ostreatus) ameliorates atherogenic lipid in hypercholesterolaemic rats. Clin exp pharmacol physiol. 2003; 30: 470-75.

35. Rahman M, Rahaman A, Fatima N, Basunia M, Hossain S. Anti-hemolytic activity of Clerodendrum viscosum is mediated by its antioxidant activity. Eur J Medicinal Plants. 2013; 31: 127-134.

36. Beevi SS, Mangamoori LN, Gowda BB. Polyphenolics profile and antioxidant properties of Raphanus sativus L. Nat Prod Res. 2012; 26:557-563.

37. Mattson MP, Cheng A. Neurohormetic phytochemicals: low-dose toxins that induce adaptive neuronal stress responses. Trends Neurosci 2006; 29: 632-639.

38. Sen, C.K. Oxygen toxicity and antioxidants: state of the art. Indian J Physiol Pharmacol. 1995; 39: 177-196.

39. Madsen HL, Bertelsen G. Spices as antioxidants. Trends Food Sci Technol. 1995; 6: 271-277.

40. Rice-Evans C, Miller N, Paganga G. Antioxidant properties of phenolic compounds. Trends in Plant Sci. 1997; 2: 152-159.

41. Diplock AT, Charleux JL, Crozier-Willi G, Kok FJ, Rice-Evans C, Roberfroid M, et al. Functional food science and defense against reactive oxidative species. Brazilian J Nutr. 1998; 80: S77-S112. 
Table 1. Antioxidant phytochemicals, activity and saponin content of $\boldsymbol{R}$. sativus extract

\begin{tabular}{|c|c|}
\hline Parameters & Content \\
\hline \multicolumn{2}{|l|}{ Antioxidant phytochemicals (mg/gm) } \\
\hline Total polyphenols (GAE) & $22.8 \pm 2.0$ \\
\hline Flavonoid (QE) & $1.15 \pm 0.10$ \\
\hline Vitamin $C(A E)$ & $0.20 \pm 0.20$ \\
\hline \multicolumn{2}{|l|}{ Antioxidant activity } \\
\hline DPPH scavenging activity $\left(\mathrm{IC}_{50}\right)$ & $7.5 \pm 0.50$ \\
\hline Hydroxyl Radical scavenging activity $\left(\mathrm{IC}_{50}\right)$ & $255 \pm 5.5$ \\
\hline Reducing power (QE) & $25.5 \pm 2.4$ \\
\hline \multicolumn{2}{|l|}{ Saponin content (mg/gm) } \\
\hline Glycyrrhizic acid equivalent/gm & $54.32 \pm 2.6$ \\
\hline
\end{tabular}

Results are mean \pm SEM (standard error of mean) of triplicate determinations.

Table 2. Effects of $\boldsymbol{R}$. sativus extract feeding on body weight, food intake, plasma lipid profile, atherogenic index, hepatic lipid content, fecal cholesterol level and plasma hepatic functional parameters.

\begin{tabular}{|c|c|c|c|c|}
\hline Parameters & Con & RSE & $\mathrm{HC}$ & HC+RSE \\
\hline \multicolumn{5}{|c|}{ Body weight \& food intake (g) } \\
\hline Weight gain & $72.0 \pm 2.40^{\mathrm{a}}$ & $63.0 \pm 2.8^{\mathrm{a}}$ & $95.0 \pm 3.7^{\mathrm{b}}$ & $73.0 \pm 4.0^{\mathrm{a}}$ \\
\hline Food intake & $18.5 \pm 1.50^{\mathrm{a}}$ & $18.0 \pm 2.0^{\mathrm{a}}$ & $21.5 \pm 1.5^{\mathrm{a}}$ & $20.5 \pm 1.6^{a}$ \\
\hline \multicolumn{5}{|c|}{ Plasma lipid profile (mg/dl) } \\
\hline $\mathrm{TC}$ & $109 \pm 2.20^{a}$ & $99.0 \pm 2.0^{\mathrm{a}}$ & $280 \pm 7.0^{b}$ & $247 \pm 5.0^{c}$ \\
\hline $\mathrm{TG}$ & $84.0 \pm 0.8^{\mathrm{a}}$ & $65.0 \pm 1.0^{\mathrm{b}}$ & $95 \pm 1.5^{c}$ & $76.0 \pm 2.0^{d}$ \\
\hline LDL-C & $52.0 \pm 2.0^{a}$ & $520 \pm 1.0^{a}$ & $208 \pm 7.0^{b}$ & $183 \pm 4.5^{\mathrm{c}}$ \\
\hline HDL-C & $40.5 \pm 1.3^{\mathrm{a}}$ & $37.0 \pm 1.2^{a}$ & $52.0 \pm 1.0^{b}$ & $50.0 \pm 1.0^{\mathrm{b}}$ \\
\hline Atherogenic index & $0.32 \pm 0.005^{\mathrm{a}}$ & $0.25 \pm 0.004^{b}$ & $0.25 \pm 0.004^{b}$ & $0.19 \pm 0.007^{c}$ \\
\hline \multicolumn{5}{|c|}{ Hepatic lipid content (mg/g of protein) } \\
\hline $\mathrm{TC}$ & $2.68 \pm 0.08^{\mathrm{a}}$ & $2.07 \pm 0.05^{\mathrm{a}}$ & $8.73 \pm 0.24^{b}$ & $5.34 \pm 0.15^{\mathrm{c}}$ \\
\hline $\mathrm{TG}$ & $4.67 \pm 0.60^{a}$ & $3.26 \pm 0.09^{a}$ & $20.36 \pm 0.56^{b}$ & $12.89 \pm 0.29^{c}$ \\
\hline \multicolumn{5}{|c|}{ Fecal cholesterol level (mg/100 mg of dry stool) } \\
\hline $\mathrm{TC}$ & $13.7 \pm 1.8^{\mathrm{a}}$ & $21.7 \pm 1.5^{\mathrm{b}}$ & $42.4 \pm 2.8^{\mathrm{c}}$ & $53.6 \pm 1.9^{d}$ \\
\hline \multicolumn{5}{|c|}{ Hepatic functional parameters (U/L) } \\
\hline ALT & $61.4 \pm 4.1^{\mathrm{a}}$ & $54.6 \pm 4.0^{\mathrm{a}}$ & $69.0 \pm 2.7^{b}$ & $61.0 \pm 1.9^{a}$ \\
\hline AST & $93.1 \pm 2.3^{\mathrm{a}}$ & $88.0 \pm 1.4^{\mathrm{a}}$ & $118 \pm 4.0^{\mathrm{b}}$ & $96.0 \pm 4.1^{\mathrm{a}}$ \\
\hline ALP & $128 \pm 4.4^{\mathrm{a}}$ & $99.0 \pm 3.0^{b}$ & $150 \pm 5.2^{c}$ & $129 \pm 5.8^{a}$ \\
\hline
\end{tabular}

Results are expressed as mean \pm SEM $(n=6)$ with duplicate determinations. Here, Con = control group; RSE = extract-fed group; $\mathrm{HC}=$ Hypercholesterolemic group; $\mathrm{HC}+\mathrm{RSE}=$ extract-fed hypercholesterolemic group; TG = Triglyceride, $\mathrm{TC}=$ Plasma total cholesterol, LDL-C = Low density lipoprotein-cholesterol, HDL-C = High density lipoprotein-cholesterol; Atherogenic index $=(\log [T G] /[H D L-C]) . A L T=$ Alanine aminotransferase, $A S T=$ Aspartate aminotransferase and $A L P=$ Alkaline phosphatase. Values in the same row which do not share a common superscript are significantly different at $\mathrm{P}<0.05$ (One-way ANOVA). 


\section{Figures with legends}
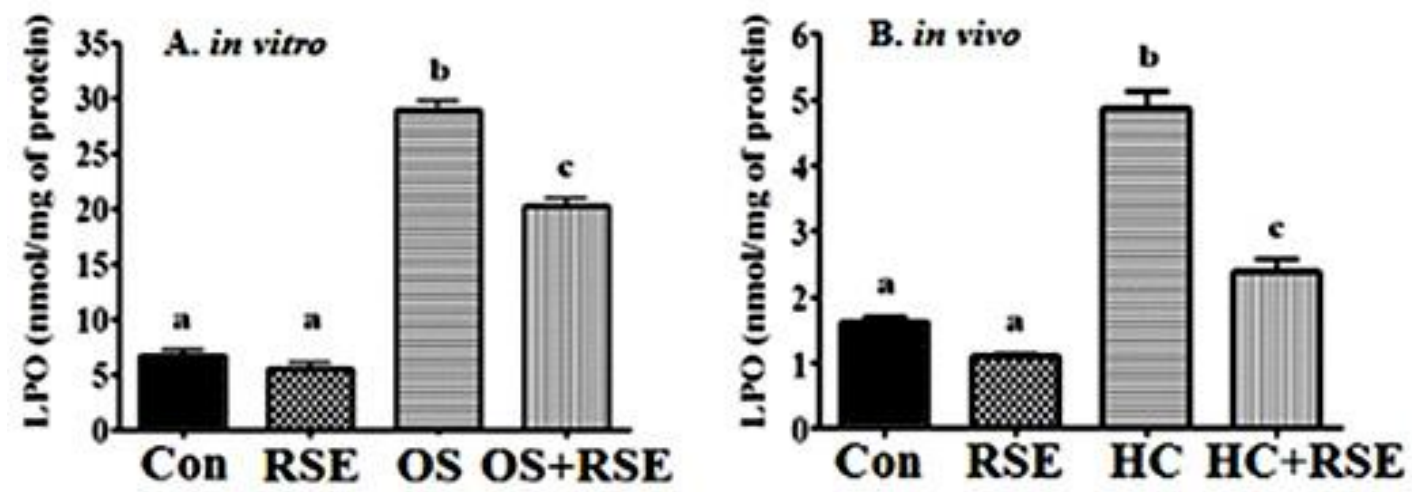

Figure 1. Effect of $R$. sativus extract on in vitro (A) Fenton's reagent-induced lipid peroxidation; (B) in vivo levels of liver LPO upon oral administration. Results are expressed as mean \pm SEM $(n=6)$. In A: Here, Con= Control homogenate; RSE $=R$. sativus extract-treated homogenate; OS = Fenton's reagent-treated homogenate without extract; OS+RSE = Fenton's reagent-treated homogenate co treated with $R$. sativus extract; In $\mathrm{B}$ : Control (Con) rats; $\mathrm{RSE}=R$. sativus extractalone fed rats; $\mathrm{HC}=1 \%$ cholesterol-fed hypercholesterolemic $(\mathrm{HC})$ rats; $\mathrm{HC}+\mathrm{RSE}=R$. sativus extract-fed hypercholesterolemic rats. Bars with different alphabets are significantly different at $p<0.05$. Data were analyzed by one-way ANOVA followed by Fisher's PLSD test for post hoc comparisons.
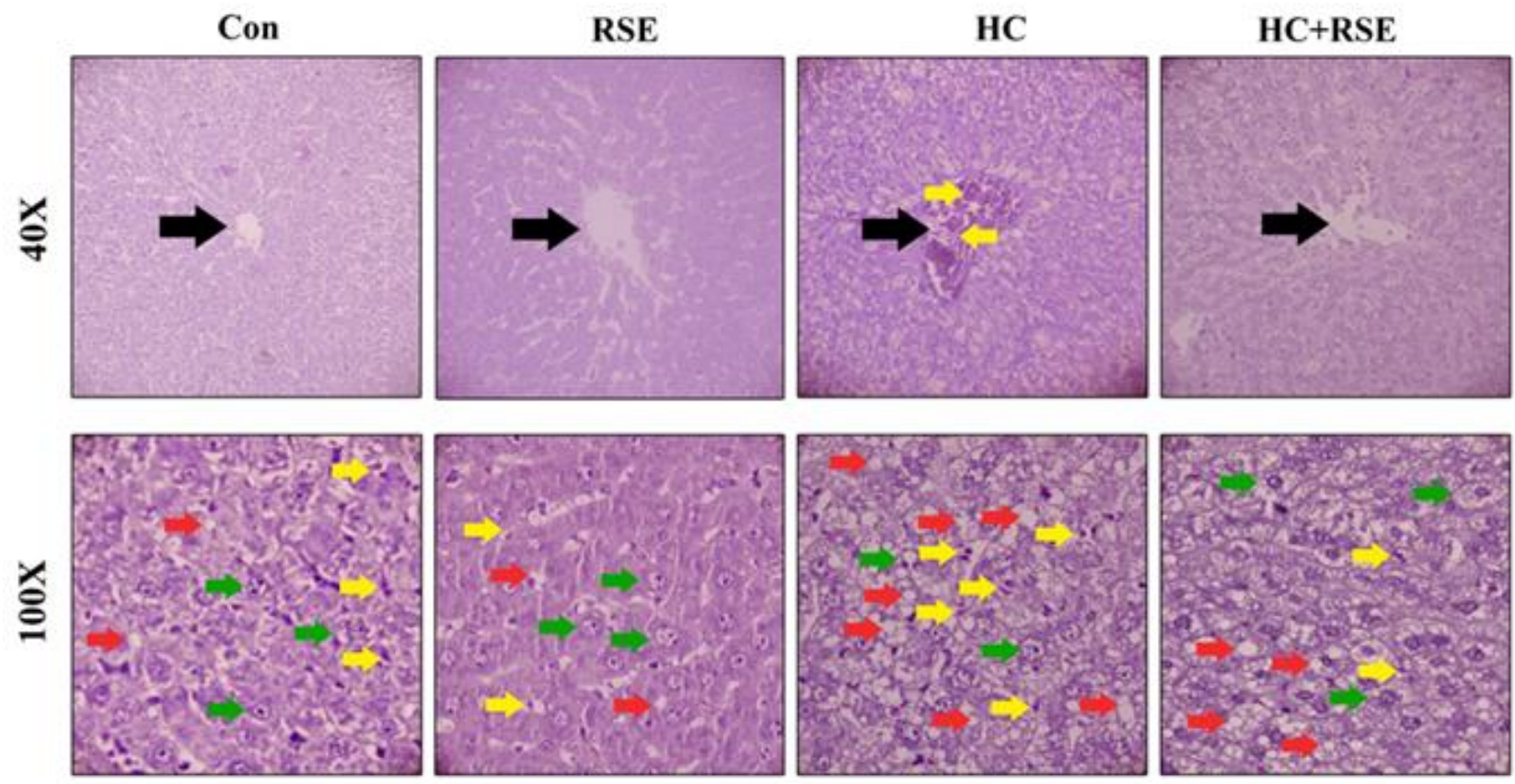

Figure 2. hematoxyline and eosin dye stained representative slices of liver. Here, Con = control group; RSE = extract treated group; $\mathrm{HC}=$ Hypercholesterolemic group; HC + RSE = extract treated hypercholesterolemic group. Black arrow shows central vein within the lobule. Green arrow shows 'hepatocytes; Yellow arrow shows inflammatory cells; Red arrow shows vacuolation due to lipid droplet deposition. 